This item was submitted to Loughborough's Research Repository by the author.

Items in Figshare are protected by copyright, with all rights reserved, unless otherwise indicated.

\title{
Using Google Analytics to evaluate the usability of e-commerce sites
}

PLEASE CITE THE PUBLISHED VERSION

PUBLISHER

(C) Springer-Verlag

VERSION

AM (Accepted Manuscript)

LICENCE

CC BY-NC-ND 4.0

REPOSITORY RECORD

Hasan, Layla, Anne Morris, and Steve Probets. 2019. "Using Google Analytics to Evaluate the Usability of Ecommerce Sites”. figshare. https://hdl.handle.net/2134/5685. 
This item was submitted to Loughborough's Institutional Repository (https://dspace.lboro.ac.uk/) by the author and is made available under the following Creative Commons Licence conditions.

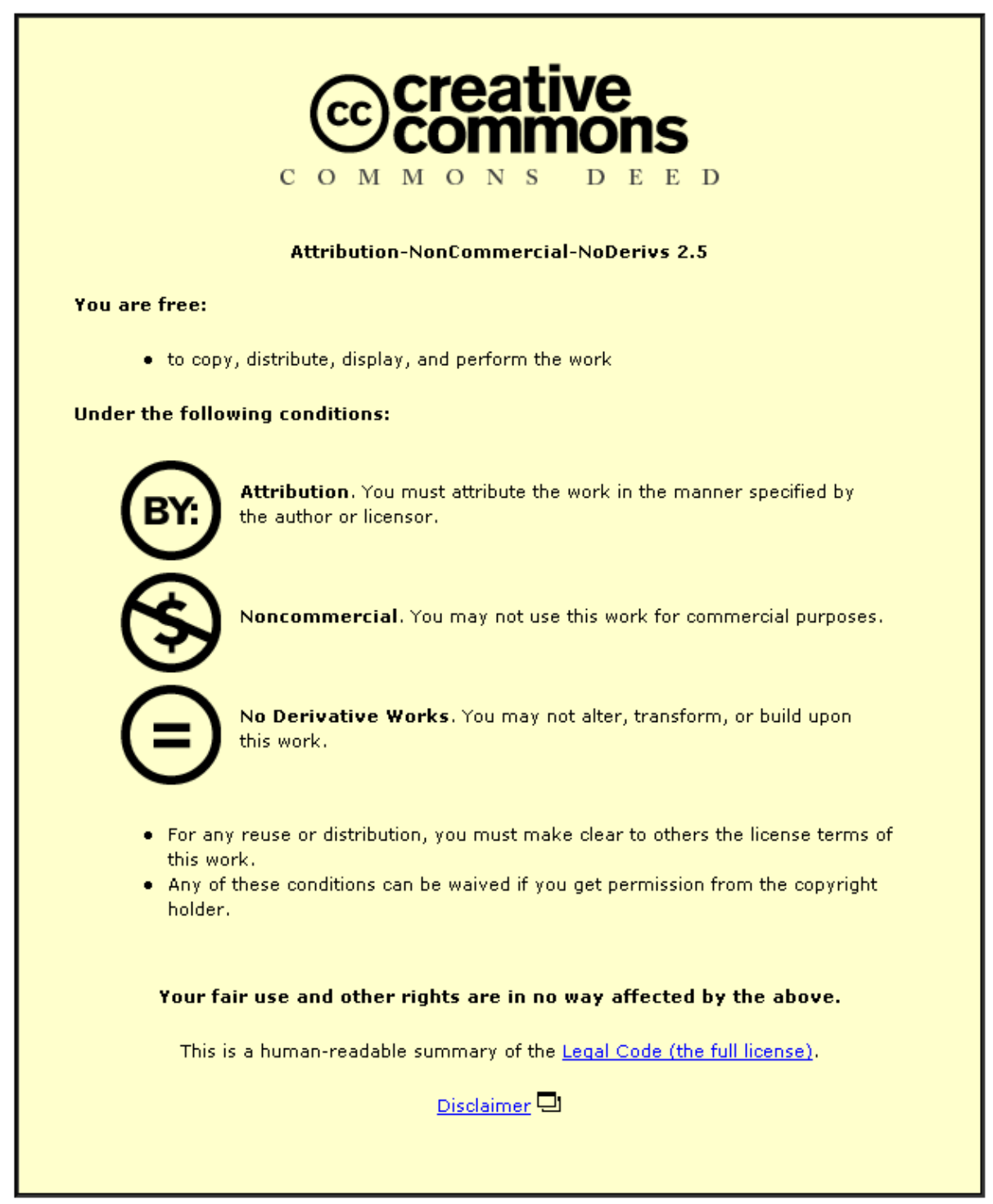

For the full text of this licence, please go to: http://creativecommons.org/licenses/by-nc-nd/2.5/ 


\title{
Using Google Analytics to Evaluate the Usability of E-commerce Sites ${ }^{1}$
}

\author{
Layla Hasan, Anne Morris, Steve Probets, \\ Department of Information Science, Loughborough University \\ Loughborough, LE11 3TU, UK \\ \{L.Hasan2, A.Morris, S.G.Probets\}@lboro.ac.uk
}

\begin{abstract}
The success of an e-commerce site is, in part, related to how easy it is to use. This research investigated whether advanced web metrics, calculated using Google Analytics software, could be used to evaluate the overall usability of e-commerce sites, and also to identify potential usability problem areas. Web metric data are easy to collect but analysis and interpretation are timeconsuming. E-commerce site managers therefore need to be sure that employing web analytics can effectively improve the usability of their websites. The research suggested specific web metrics that are useful for quickly indicating general usability problem areas and specific pages in an e-commerce site that have usability problems. However, what they cannot do is provide in-depth detail about specific problems that might be present on a page.
\end{abstract}

Keywords: Web Analytics, Google Analytics, usability, e-commerce web sites.

\section{Introduction}

Ease-of-use is one of the most important characteristics of web sites, especially those provided by e-commerce organisations [1]. Norman and Nielsen, for example, stress the importance of making e-commerce sites usable. They do not regard good usability as a luxury but an essential characteristic if a site is to survive [2]. Nielsen explained the reasons behind this when he stated that the first law of e-commerce is that, if users are unable to find a product, they cannot buy it [3].

Despite the importance of good usability in e-commerce web sites, few studies were found in the literature that evaluated the usability of such sites. Those that were found, employed usability methods that involved either users or evaluators in the process of identifying usability problems. For example, Tilson et al.'s study asked sixteen users to use four e-commerce web sites and report what they liked and disliked [4]. Other studies have employed heuristic evaluation [5], user testing [6], or these two methods together in their evaluations of e-commerce sites [7]. However, little research has employed web analytic tools which automatically collect statistics regarding the detailed use of a site, in the evaluation of e-commerce web sites, although

1 Published in M. Kurosu (Ed.): Human Centered Design, HCII 2009, LNCS 5619, pp. 697-706, 2009.

(C) Springer-Verlag Berlin Heidelberg 2009 
these tools have been employed to evaluate other types of web site and proved to be useful in identifying potential design and functionality problems $[8,9,10]$.

\section{Web Analytics}

Web analytics is an approach that involves collecting, measuring, monitoring, analysing and reporting web usage data to understand visitors' experiences. Analytics can help to optimise web sites in order to accomplish business goals and/or to improve customer satisfaction and loyalty $[11,12,13]$.

There are two common methods used by web analytics tools to collect web traffic data. The first involves the use of server-based log-files, and the second requires client-based page-tagging. Web analytics started with the analysis of web traffic data collected by web servers and held in log-files [14,15].

Many of the earlier studies that used web analytics to evaluate and improve different aspects of web sites used log-file based web analytics and therefore employed traditional metrics based on log-file analysis $[8,9,10]$. Various metrics were employed by these studies to evaluate and improve the design of the web sites with regard to four areas: content, navigation, accessibility and design. Specifically, these studies employed six metrics in evaluating and improving content (exit pages [8], search terms, referrer, search engines, top entry and exit pages and time on site [9]), three metrics to improve navigation (error pages, search terms [8], and path analysis $[8,10]$ ), four metrics to evaluate accessibility (search terms $[8,9,10]$, search engines [9], referrer [8,10] and entry pages [8]) and two metrics to provide advice regarding the design (browser [8,10] and platform statistics [8]). These studies suggested that metrics are useful in evaluating different aspects of web sites' design [8,9,10]. However, one of these studies indicated that metrics need to be augmented by further investigation involving actual users of a web site [10]. Only one of these studies suggested a framework or matrix of metrics for evaluating web sites; Peacock's study suggested a framework of twenty log-based metrics for evaluating and improving user experience of museum web sites. This framework was an initial step towards creating an evaluation model for online museum services.

However, inaccuracies of using log-files as a data source were noticed by both web analytics vendors and customers [14]. This led to the emergence of page-tagging techniques as a new source for collecting data from web sites. The page-tagging approach involves adding a few lines of script to the pages of a web site to gather statistics from them. The data are collected when the pages load in the visitor's browser as the page tags are executed $[14,15]$. Page-tagging is typically much more accurate than using web server log-files and is a more informative source for web analytics applications $[14,15]$. There are a number of reasons for this, one is that most page tags are based on cookies to determine the uniqueness of a visitor and not on the IP address (as is the case of the web server log files), another is that non-human user agents (i.e. search engines, spiders and crawlers) are excluded from measurement and reporting because these user agents do not execute the JavaScript page tags [14,15]. An example of a Web Analytic tool that uses the page-tagging approach and which had a major effect on the web analytics' industry is Google Analytics [14]. In 2005 Google pur- 
chased a web analytics firm called Urchin software and subsequently released Google Analytics (GA) to the public in August, 2006 as a free analytics tool.

At least two studies have recognised the appearance of Google Analytics software and used this tool to evaluate and improve the design and content of web sites (a library web site [17] and an archival services web site [18]). Both used the standard reports from GA without deriving specific metrics. One of these studies used eight reports: site overlay, content by titles, funnel navigation ${ }^{2}$, visitor segmentation, visualized summary report, information on visitors' connection speed and computer configuration [17]. The other used three reports: referrals, funnel navigation and landing pages [18]. These studies suggested that the GA tool could be a useful tool and have specific relevance to user-centred design since GA's reports enable problems to be identified quickly and help determine whether a site provides the necessary information to their visitors.

\section{Aims and Objectives}

The purpose of this paper is to illustrate the value and use of Google Analytics (GA) for evaluating the usability of e-commerce web sites by employing advanced web metrics. The specific objectives for this research were:

- To investigate the potential usability problem areas identified by GA software;

- To assess the main usability problem areas in three e-commerce web sites using comprehensive heuristic guidelines;

- To compare issues raised by GA software to problems identified by the web experts who evaluated the sites using heuristics approaches.

\section{Methodology}

This research involved three e-commerce case studies. It compared the usability findings indicated by GA software to a heuristic evaluation of the sites conducted by experts.

In order to use GA software to track usage of the e-commerce sites it was necessary to install the required script on the companies' web sites. The sites' owners identified key business processes in each site and GA was set up to assess the usability of web pages encountered by users in completing these processes. The usage of the websites was then monitored for three months.

The heuristic evaluation involved devising a set of comprehensive heuristics, specific to e-commerce websites. They were derived from a thorough review of the HCI literature and comprised six major categories: navigation, internal search, architec-

2 The funnel navigation report involves an analysis of the navigation paths followed by visitors to a web site while going through a number of identified steps (pages) to complete a key business process. 
ture, content and design, customer service, and purchasing process. A total of five web experts evaluated the sites using the heuristic guidelines.

\section{Results}

Thirteen key web metrics were identified that could provide an alternative to heuristic evaluation in determining usability issues. Specifically, these metrics were chosen so that, either individually or in combination, they could identify potential usability problems on e-commerce sites. These metrics are presented in Table 1 together with the results for the three sites.

Table 1. Web Metrics and Results.

\begin{tabular}{|c|c|c|c|c|c|}
\hline No & \multicolumn{2}{|l|}{ Metric } & Site 1 & Site 2 & Site 3 \\
\hline 1 & \multicolumn{2}{|c|}{ Average page views per visit } & 17.00 & 12.56 & 5.62 \\
\hline \multirow[t]{3}{*}{2} & $\begin{array}{l}\text { Percentage } \\
\text { of time spent } \\
\text { visits }\end{array}$ & $\begin{array}{l}\text { Percentage of low } \\
\text { time spent visits } \\
\text { (between } 0 \text { seconds } \\
\text { and } 3 \text { minutes) }\end{array}$ & $60.16 \%$ & $76.76 \%$ & $77.75 \%$ \\
\hline & & $\begin{array}{l}\text { Percentage of me- } \\
\text { dium time spent } \\
\text { visits (between } 3 \\
\text { and } 10 \text { minutes) }\end{array}$ & $21.67 \%$ & $14.48 \%$ & $13.23 \%$ \\
\hline & & $\begin{array}{l}\text { Percentage of high } \\
\text { time spent visits } \\
\text { (more than } 10 \mathrm{mi}- \\
\text { nutes) }\end{array}$ & $18.17 \%$ & $7.77 \%$ & $10.01 \%$ \\
\hline \multirow[t]{3}{*}{3} & $\begin{array}{l}\text { Percentage } \\
\text { of click } \\
\text { depth visits }\end{array}$ & $\begin{array}{l}\text { Percentage of low } \\
\text { click depth visits } \\
\text { (two pages or few- } \\
\text { er) }\end{array}$ & $31.29 \%$ & $32.36 \%$ & $59.20 \%$ \\
\hline & & $\begin{array}{l}\text { Percentage of me- } \\
\text { dium click depth } \\
\text { visits (between } 3 \text { to } \\
\text { the value of metric } \\
\text { 1) }\end{array}$ & $42.57 \%$ & $40.98 \%$ & $22.99 \%$ \\
\hline & & $\begin{array}{l}\text { Percentage of high } \\
\text { click depth visits } \\
\text { (more than the val- } \\
\text { ue of metric } 1 \text { ) }\end{array}$ & $26.14 \%$ & $26.66 \%$ & $17.81 \%$ \\
\hline 4 & \multicolumn{2}{|c|}{ Bounce rate } & $22.77 \%$ & $30.50 \%$ & $47.58 \%$ \\
\hline 5 & \multicolumn{2}{|c|}{ Order conversion rate } & $1.07 \%$ & $0.37 \%$ & $0.25 \%$ \\
\hline 6 & \multicolumn{2}{|c|}{ Average searches per visit } & 0.07 & 0.05 & NA \\
\hline 7 & \multicolumn{2}{|c|}{ Percent of visits using search } & $2.14 \%$ & $3.16 \%$ & NA \\
\hline 8 & \multicolumn{2}{|c|}{ Search results to site exits ratio } & 0.79 & 0.53 & NA \\
\hline 9 & \multicolumn{2}{|c|}{ Cart start rate } & $5.94 \%$ & $2.89 \%$ & NA \\
\hline 10 & \multicolumn{2}{|c|}{ Cart completion rate } & $18.07 \%$ & $12.98 \%$ & NA \\
\hline
\end{tabular}




\begin{tabular}{lllll}
\hline 11 & Checkout start rate & $3.63 \%$ & $1.02 \%$ & $1.7 \%$ \\
12 & Checkout completion rate & $29.55 \%$ & $36.61 \%$ & $15 \%$ \\
13 & Information find conversion rate & {$[0.23 \%$ to } & {$[0 \%$ to } & {$[0 \%$ to } \\
& (ranges for the selected pages) & $4 \%]$ & $2.41 \%]$ & $2.71 \%]$ \\
\hline
\end{tabular}

Where appropriate, further explanation behind some of these metrics will be outlined in the following sections, specifically bounce rate, information find conversion rate, order conversion rate, cart completion rate and checkout completion rate will be explained in footnotes.

An analysis of the usability problems uncovered by these metrics enabled websites to be evaluated in six potential problem areas. These were: navigation, internal search, architecture, content/design, customer service and purchasing process. The following sections present the results obtained from the metrics; these are then compared to the findings obtained from the heuristic evaluators.

\section{Analysis of Results}

\subsection{Navigation}

The metrics used to investigate the general usability of a site indicated that all three sites had potential navigational problems, as shown by bounce rate ${ }^{3}$ (metric 4). Site 1 had the lowest value for this metric among the three sites, whilst site 3 had the highest value. Further evidence of navigational problems on site 3 was obtained due to the low average number of page views per visit (metric 1 ).

However, other metrics seemed to contradict the notion of navigational problems on sites 1 and 2, for example:

- The low values for metrics 6 and 7 (average searches per visit and percent of visits using search) could suggest that these two sites either had good navigation so that a search facility was not needed or alternatively that there were problems with the search facilities (see Section 6.2).

- Metric 3 (percentage of click depth visits) showed that sites 1 and 2 received high percentages of medium depth visits (between 3 to 17 and 3 to 12, respectively).

- Metric 1 (average page views per visit) showed that site 1 and 2 had a relatively high number of pages views per visit (17 and 12.56 respectively) compared to site 3 (5.62).

The heuristic evaluators confirmed these findings; although all the sites had some navigation problems (such as misleading links) a smaller number of problems were identified on sites 1 and 2 (7 and 11 problems respectively), while a larger number of problems (42 problems) and the most serious problems were identified on site 3.

3 Bounce rate metric: Percentage of single page visits, i.e. visits in which a visitor left the site after visiting only the entrance page. 


\subsection{Internal Search}

The metrics used to examine the usability of the internal search and the general usability of a site indicated that the internal search facilities of sites 1 and 2 had usability problems. Metric 6 (average searches per visit) and metric 7 (percent of visits using search) showed that the usage level of the internal search facilities of sites 1 and 2 was low. However, the relatively high number of pages viewed on sites 1 and 2 (metrics 1 and 3) could mean that visitors relied on navigation rather than the internal search of the sites to find what they needed. To determine if there were problems with the internal search on these sites, the value of metric 8 (search results to site exits ratio) for sites 1 and 2 was considered. This indicated that users were leaving the sites immediately after conducting a search and that these sites probably did have usability problems related to the inaccuracy of the search results.

The heuristic evaluators confirmed that the internal search facilities of these sites had usability problems. They identified problems with the search facilities, which were limited (site 3 did not have one), and with the results provided, which were often inaccurate.

\subsection{Architecture}

The metrics used to investigate the general usability of a site indicated that all the sites had potential usability problems with their information architecture. This was indicated by the large number of visitors who spent little time on the sites (i.e. their visits did not exceed 3 minutes in duration) (metric 2). Other metrics explained the significance of the architectural problems on these sites. For example, the low rate of usage of the internal search facilities of sites 1 and 2 (metrics 6 and 7), together with the high percentages of visits with medium click depth for sites 1 and 2 (metric 3) provided a potential indication that the architecture of sites 1 and 2 had fewer problems as visitors were able to navigate through these sites, implying that their search facilities may not be needed. However, the low value of the average page views per visits metric for site 3 (metric 1 ), together with the high percentage of visits with low click depth for site 3 (metric 3 ) provided a potential indication that site 3 had a complex architecture and that users could not navigate within it.

Although the heuristic evaluators did not report major problems with the architecture of sites 1 and 2; they did think that the order of the items on the menu of site 2 was illogical. However, as may be expected from the metrics, they found major problems with the overly complex architecture of site 3 .

\subsection{Content/Design}

The metrics used to examine the general usability of a site indicated that the three sites had potential usability problems with some of their content. The percentages of visits in terms of the number of pages viewed (metric 3) indicated that visitors to the three sites did not appear to be interested in the content of the sites, however the degree to which content was found to be uninteresting differed among the sites. Site 3 
had a high percentage of low depth visits where most visitors viewed 2 pages or fewer, indicating that most visitors were not interested in its content. Conversely, sites 1 and 2 had high percentages of medium depth visits (most visitors to sites 1 and 2 viewed between 3 and 17 pages, and between 3 and 12 pages respectively), indicating that visitors to these sites were more interested in the sites' content or products. Although more pages were viewed on sites 1 and 2, the metrics indicate that most visitors spent less than 3 minutes on all three sites (metric 2). Taken together these metrics imply that there are content problems on all three sites, but that the problems are worse on site 3 .

The heuristic evaluators reinforced these findings. They identified a large number of content problems on the three sites. These included: irrelevant content, inaccurate information and missing information about products. The largest number of content problems were found on site 3 ( 21 problems) and the lowest on site 1 (4 problems).

The bounce rate metric, which is used to investigate the global design flaws in a site's page layout, also indicated that all the sites had potential usability problems in their content or design (metric 4). Bounce rate is the percentage of visits where visitors left the site after visiting only its entrance page. High bounce rate implies that either users are uninterested in the sites' content or that the design is unsuitable for the users. From the metrics it is difficult to determine if a high bounce rate is due to content or design problems. By contrast heuristic evaluation was able to identify a large number of design-specific problems with the three sites. They identified fourteen problems in sites 1 and 3 and nine in site 2. Examples of these problems include inappropriate page design and broken images. This is an area where heuristic evaluation is more precise than analytics. The analytics were able to identify potential issues, but the heuristics were able to be more specific in identifying whether problems were content or design specific.

The metrics of the top ten landing pages (bounce rate, entrance searches and entrance keywords) also identified specific pages within the sites that had possible usability problems. The top ten landing pages in each site included the home page in each site and various pages illustrating products (nine in site 1 , seven in site 2 and six in site 3). The entrance keywords/searches metrics indicated that users had arrived at these pages with specific intentions, yet the high bounce rates from them suggests that the users were unimpressed with either the content or the design of the pages. The heuristic evaluators confirmed the existence of specific content and design usability problems in the product category pages and in the home pages of the three sites (i.e. irrelevant content, inappropriate page design and unaesthetic design).

\subsection{Customer Service}

Prior to the analysis, the customer support pages were identified by the owner of each site (12 pages for site 1, 18 for site 2 and 20 for site 3 ). The low information find conversion rate 4 metric provided evidence that visitors could not easily find and visit the customer support pages (metric 13). This suggests that either the architecture of the

\footnotetext{
4 Information find conversion rate metric: Percentage of visits to a specific page that displays important customer support information.
} 
sites are at fault or the search facilities are poor. These findings were supported by the heuristic testing that identified navigation problems on the three sites particularly with respect to customer support links being misleading.

\subsection{Purchasing Process}

Metrics related to the purchasing process provided potential indications of usability problems in the overall purchasing process of the three sites. For example, the low values of the order conversion rate ${ }^{5}$ metrics (metric 5 ) of all sites indicated that few visits resulted in an order. When viewed alongside, the relatively low values of the percentage of high time spent visits metrics (metric 2), this suggests that few visitors were engaged in purchasing activity on the three sites. The low cart completion rate ${ }^{6}$

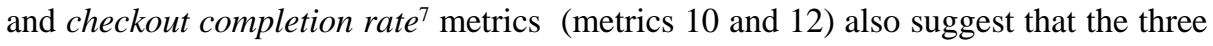
sites had usability problems in their purchasing processes.

The heuristic evaluators also experienced problems with the purchasing process of all three sites and identified usability problems regarding obstacles and difficulties that users might face while trying to make a purchase. The largest number of problems were identified on site 1 (6 problems) while four and two problems were identified on sites 2 and 3 respectively.

A similar issue was found with specific pages that make up the purchasing process. The metrics indicated that users were not only having difficulty in completing the purchasing process, but that they were also having difficulty in beginning or starting the process. Two purchasing process metrics (cart start rate and checkout start rate) and the funnel report indicated potential usability problems in this area:

- The low value of the cart start rate metric (which showed few users added anything to the shopping cart) (metric 9) suggests that sites 1 and 2 had usability problems on their product pages. This was confirmed by the heuristic evaluation method, which identified specific problems on these pages: navigation problems (on sites 1 and 3), design problems (on site 2), and content problems (on all three sites).

- The values of the checkout start rate metrics were lower than the values of the cart start rate metrics (metrics 11 and 9). This means that some customers, who added a product to a shopping cart, did not begin the checkout/payment process. This suggests that the pages containing the 'go to checkout' button had usability problems. This was indeed confirmed by the heuristic evaluators who experienced navigational problems on these pages in all three sites. In addition, the evaluators thought the ordering process on site 1 was too long.

5 Order conversion rate metric: Percentage of visits that result in an order.

6 Cart completion rate metric: Percentage of visits that result in an order after items have been added to a shopping cart and then the checkout process has been performed.

7 Checkout completion rate metric: Percentage of visits that result in an order once the 'checkout' button has been selected (i.e. it does not include the process of adding items to the shopping cart). 
More information about the purchasing process was obtained by the funnel reports, which were used to identifying possible usability problems regarding specific pages in the purchasing process of the three sites; these were confirmed by the heuristic evaluators. An example of how the funnel was used is illustrated in the following example: The statistics of the sign-in page of site 1 showed that few visitors (33\%) proceeded to the next step in the purchasing process. Instead, many visitors went to the 'forgot account number' page to get their account number (18\%); left the site (13\%); or went to the 'login error' page by entering wrong login information (11\%). Therefore, the usability problem inferred from these statistics was that it was not easy for visitors to log into the site through the sign-in page. The heuristic evaluators also had difficulties logging into site 1 because the process requires both an account number and an email address. The evaluators indicated that this is cumbersome and that users may have difficulty remembering their account details.

The funnel report provided indications of other potential usability problems on other specific pages on the three sites. These problems were also identified by the heuristic evaluators, however, the heuristic evaluators were able to provide more detail about the specific problems on these pages and how they related to navigation, design and content issues. Although the metrics were able to indicate possible problems, again the heuristic evaluators were able to be more specific.

It is worth mentioning that the heuristic evaluators reported other usability problems on the sites such as the lack of security and privacy, inconsistent design, and the lack of functions/capabilities/information on the sites. These problems could not be identified from the metrics.

\section{Conclusion}

This research identified specific web metrics that can provide, quick, easy, and cheap, indications of general potential usability problem areas on e-commerce web sites. In some instances they can also be used to identify problems on specific pages, however, not in all instances. By contrast, the results showed that the heuristic evaluators were able to identify detailed specific usability problems.

The suggested thirteen metrics can be used to provide a continual overview of a site's usability and are an important tool for indicating when potential problems may be being experienced. However, to get a more thorough appreciation of the issues other usability techniques (such as heuristic evaluation) are needed. In some aspects the web metrics have advantages - for example metrics can provide information regarding the financial performance of the site in terms of its ability to generate revenue whereas heuristic evaluators cannot provide this information.

The results offer a base for future research. The next step will be to develop a framework using GA as a first step in the process of identifying usability problems of an e-commerce web site. Other usability methods including heuristic evaluation will also be employed to identify the specific usability problems on the specific areas and pages on the web site indicated by the web metrics. The goal is to provide a framework which enables specific usability problems to be identified quickly and cheaply 
by fully understanding the advantages or disadvantages of the various usability methods.

\section{References}

1. Najjar, L.: Designing E-commerce User Interfaces. In: R. W. Proctor, K-P. L., Vu. (eds.) Handbook of Human Factors in Web Design, pp. 514--527. Mahwah, NJ: Lawrence Erlbaum (2005)

2. Nielsen, J., Norman D.: Web-Site Usability: Usability on The Web Isn't A Luxury. Information Week, http://www.informationweek.com/773/web.htm

3. Nielsen, J.: Usability 101: Introduction to Usability. Useit.com, http://www.useit.com /alertbox/20030825.html

4. Tilson, R., Dong, J., Martin, S., Kieke E.: Factors and Principles Affecting the Usability of Four E-commerce Sites. In: $4^{\text {th }}$ Conference on Human Factors and the Web (CHFW), AT\&TLabs, USA (1998)

5. Chen, S.Y., Macredie, R.D.: An Assessment of Usability of Electronic Shopping: a Heuristic Evaluation. J. International Journal of Information Management. 25, 516--532 (2005)

6. Freeman, M.B., Hyland, P.: Australian Online Supermarket Usability. Technical Report, Decision Systems Lab, University of Wollongong (2003)

7. Barnard, L., Wesson, J.: A Trust Model for E-commerce in South Africa. In: SAICSIT 2004, pp. 23--32, 2004

8. Peacock, D.: Statistics, Structures \& Satisfied Customers: Using Web Log Data to Improve Site Performance. In: Museums and the Web 2002, Boston (2003)

9. Xue, S.: Web Usage Statistics and Web Site Evaluation. J. Online Information Review, 28(3), 180--190 (2004)

10. Yeadon, J.: Web Site Statistics. J. Vine, 31(3), 55--60 (2001)

11. Malacinski, A., Dominick, S., Hartrick, T.: Measuring Web Traffic, Part1, http://www.ibm. .com/developerworks/web/library/wa-mwt1

12. McFadden, C.: Optimizing the Online Business Channel with Web Analytics, http://www. webanalyticsassociation.org/en/art/?9

13. Web Analytics Association, http://www.webanalyticsassociation.org

14. Kaushik, A.: Web Analytics, an Hour a Day. Wiley Publishing, Inc (2007)

15. Peterson, E.: Web Analytics Demystified. Celilo Group Media and CafePress, (2004)

16. A Visual History of Web Measurement, Web Site Measurement, http://www.websitemeasur ement.com

17. Fang W.: Using Google Analytics for Improving Library Website Content and Design: A Case Study. J. Library Philosophy and Practice. 1--17(2007)

18. Prom C.: Understanding On-line Archival Use through Web Analytics. ICA-SUV Seminar, Dundee, Scotland (2007), http://www.library.uiuc.edu/archives/workpap/PromSUV2007.pdf 